\title{
Evaluation of the risk of decay of wooden beams embedded in internally insulated walls by long-term measurements
}

\author{
Timo De Mets ${ }^{1, *}$, and Antoine Tilmans ${ }^{1}$ \\ ${ }^{1}$ Belgian Building Research Institute, Energy Division, Av. P. Holoffe 21, 1342 Limelette, Belgium
}

\begin{abstract}
Internal insulation of existing walls is crucial to increase the energy efficiency of the building stock. However, this technique influences the drying potential of the wall and could consequently increase the decay risk of wooden beams embedded in the existing wall. We performed a long-term field study on different test walls with wooden beams. This paper discusses 2.5 years of measurements by analysing the moisture contents at the beam ends for the different test walls. The use of vapour open insulation materials has only a slightly favourable impact. On the other hand, measures to lower the moisture content of the wall have a significant effect, either by locally interrupting the insulation at the beam junction or by applying a water repellent treatment. Controlling the rain load on the wall seems to be a key point towards a moisturesafe application of internal insulation with embedded wooden beams.
\end{abstract}

\section{Introduction}

With a share of $40 \%$ of the energy consumption, buildings are the largest consumer in Europe [1]. Renovation of existing buildings can significantly lower the $\mathrm{CO}_{2}$-emission and is thus an important step in tackling climate change. Walls of buildings in urban context or with worth-preserving façades can often only be insulated from the inside. Internal insulation however should be executed with care, as it changes the hygrothermal behaviour of the wall and increases the risk of moisture-related problems such as internal condensation, frost damage and mould growth.

Multiple studies tried to identify and cope with the hygrothermal risks related to internal insulation. The brick type and thickness and the amount of wind-driven rain absorbed by the masonry have an impact on the moisture levels in the construction [2-4]. To lower the moisture content of the existing wall, capillary active insulation systems are often promoted; these systems are vapour open and thus allow more inward drying of the masonry than vapour tight systems [3-8].

Unavoidably, even when applying vapour open systems, the drying potential of the existing wall decreases after applying internal insulation, due to its lower temperature. Walls exposed to wind-driven rain can therefore reach critical moisture contents. In the common case of old buildings having wooden beams embedded in their walls, internal insulation can increase the risk of wood decay of the beam ends. Next to this outdoor moisture source, risk of wood decay could increase when warm moist air reaches the cold beam end and condensates. To prevent this convective transport of indoor air, the junction between beam and masonry should be sealed airtightly [9-11].
The impact of internal insulation on wooden beams have been studied several times. A first group of publications report case studies, investigating the moisture conditions of the beam for the examined building [11-16]. However, it is often difficult to extrapolate the conclusions of these measurements to other buildings. The second group discusses field tests, comparing different situations either in outdoor $[9,26]$ or laboratory conditions [2, 10, 17]. The last group has numerically modelled the beam junction [17-20]. These numerical calculations are powerful as slow hygrothermal transport phenomena can be simulated in a matter of hours or days. By varying different parameters of a simulation model, the impact of each of these parameters on the hygrothermal behaviour could be examined. However, the results strongly depend on input data and boundary conditions. Moreover, generally some important simplifications need to be taken, for instance the 2 dimensional simplification of the 3 dimensional beam. Another example is the assumption of a homogeneous masonry, neglecting the impact of the hygric resistance of the brick-mortar joint [21-24], the differences in liquid transport between brick and mortar, and the heterogeneity between and inside old bricks [25].

Despite this abundant research, no clear and general consensus has been reached to safely apply internal insulation of existing walls with embedded wooden beams. Some questions remain unanswered or different opinions exist, for instance which insulation materials to be used or the impact of wind-driven rain. As a lot of existing buildings contain wooden elements, this uncertainty hampers the application of internal insulation - and thus the energetic renovation of buildings - on a larger scale.

\footnotetext{
*orresponding author: timo.de.mets@bbri.be
} 
To study which parameters have an impact on the hygrothermal behaviour of internally insulated walls with embedded wooden beams, we performed a longterm field study on different adjacent test walls. Comparing the behaviour of these walls will give more insight into the moisture-safe solution.

This paper discusses the main results of the longterm field study. The next chapter describes in detail the full-scale test set-up that has been used for the measurements. The third section discusses the results of the measurements. The final section summarizes the main conclusions of the paper.

\section{Test set-up}

A test house located on the research facility of the Belgian Building Research Institute (BBRI) is used to investigate the hygrothermal performance of wooden beams embedded in masonry walls. The test house consists of two chambers with an open south-oriented side (angle of $190^{\circ}$ clockwise from north). In these two openings of $3 \mathrm{~m}$ by $2 \mathrm{~m}$, different masonry walls with a thickness of $30 \mathrm{~cm}$ are constructed (Fig. 1) using recuperation bricks and a hydraulic lime mortar. No external rendering is applied. This wall composition corresponds to the walls of a common Belgian dwelling built prior to 1945 . Each masonry wall is separated using cellular glass, limiting the thermal and hygric influence between the walls. The walls were constructed in December 2015. Measurement results are however only presented starting from September 2017, as before, there is a clear influence of the built-in moisture.

In total, nineteen wooden beams are embedded in the different walls at a distance of $9 \mathrm{~cm}$ from the indoor brick surface (Fig. 2). All beam junctions are airtightly sealed, either by using a flexible foam or a tape. No flooring or ceiling was installed. Each wooden beam represents a different situation. Firstly, different insulation materials are used to insulate the masonry walls from the inside. Next to that, the beam is embedded in different ways. Thirdly, the thermal insulation of one wall is interrupted, creating a thermal bridge. Finally, a water repellent is applied on a wall.

To study the influence of these different situation on the hygrothermal behaviour of the beams, sensors are added to measure temperature (T-type thermocouple), relative humidity (capacitive sensor) and wood moisture content (resistive moisture pin). This paper focuses mainly on the moisture content of the beam end. The moisture content sensor is positioned in the middle (both horizontally and vertically) of the end side of the beam.

The indoor climate of both test chambers is controlled and kept at $20^{\circ} \mathrm{C}$ and $50 \%$ RH during the whole measurement period. The outdoor temperature, relative humidity and wind-driven rain (using a rain gauge) are monitored (Fig. 3). The annual amount of wind-driven rain equals $135 \mathrm{~mm}$ in $2017,125 \mathrm{~mm}$ in 2018 and $187 \mathrm{~mm}$ in 2019 and is higher in wintertime than in summertime.

The next subsections detailly describe the different walls that are investigated in this paper.

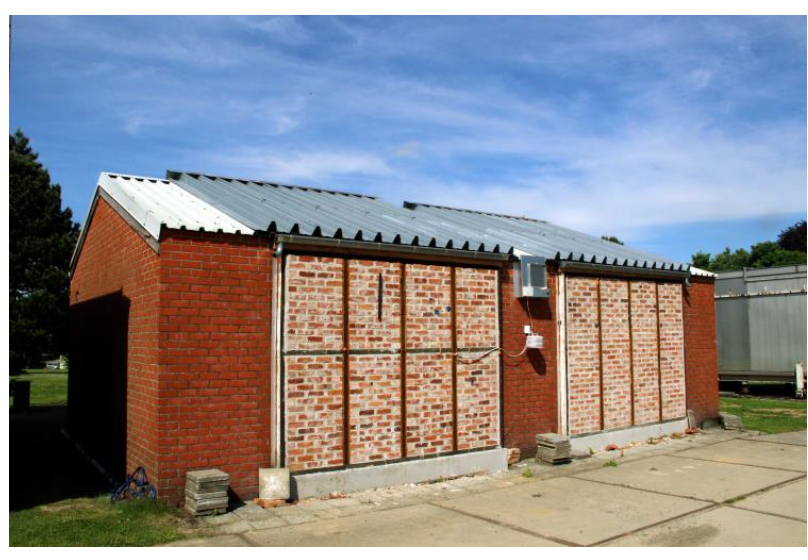

Fig. 1. Test house from the outside. The rain gauge and T/RHsensor (with radiation shield) are positioned between the two test chambers.

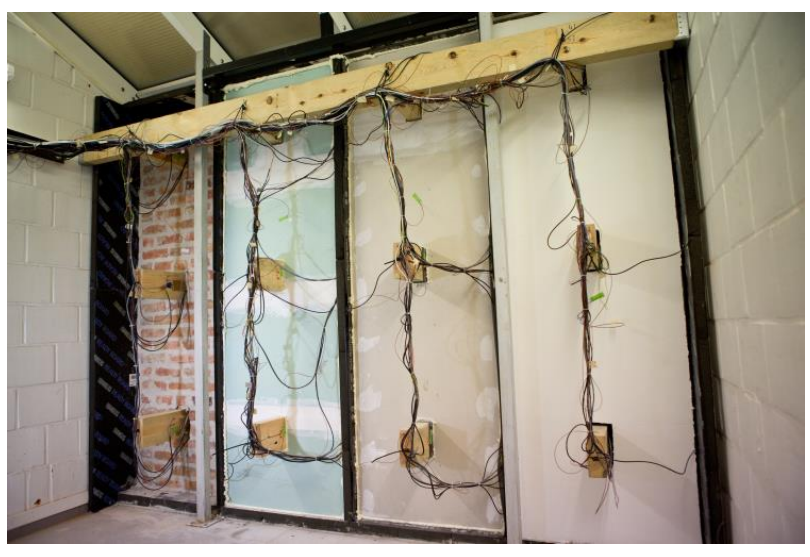

Fig. 2. One of the two test chambers from the inside. From left to right: non-insulated wall, EPS, mineral wool and calcium silicate. The three beams per wall represent a different connection between masonry and beam. The top beam parallel to the wall only serves as a structural support for the wall.

\subsection{Insulation materials}

Capillary active insulation systems are often promoted, as they allow more inward drying of the masonry than vapour tight systems. The impact of different insulation materials on the hygrothermal behaviour of wooden beams has been investigated previously [2, 11-12, 28], however no general agreement seems to exist on which insulation type to use by default.

In this paper, the measurements on a non-insulated wall and four walls with different internal insulation materials are discussed (Table 1). Expanded polystyrene (EPS) is a vapour tight system. Calcium silicate (CASI) and perlite are both capillary active systems. As mineral wool (MW) is vapour open and non-hygroscopic, a smart vapour retarder (SVR) has been added. This vapour barrier has a moisture-dependent vapour resistance in order to prevent internal condensation in wintertime, while allowing drying out in the summer. The lower and upper limit of the vapour resistance range are however achieved at respectively a very high and very low relative humidity. Under normal conditions, these extreme values are not reached, leading to a lower range of vapour resistance in practice. 

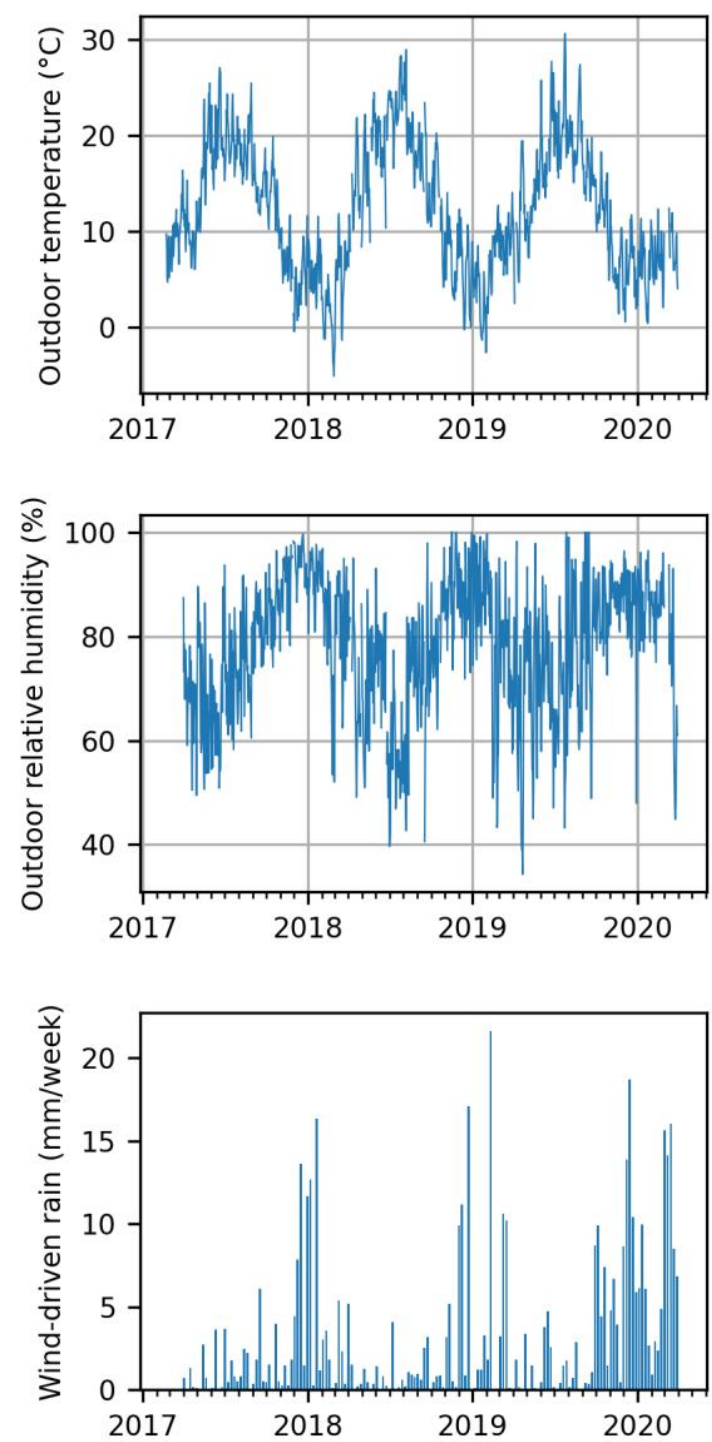

Fig. 3. Outdoor climate conditions during the measurements (daily average for temperature and relative humidity).

Table 1. A non-insulated and four different internally insulated walls are discussed in this paper. EPS and MW are traditional materials, CASI and perlite are capillary active.

\begin{tabular}{|c|c|c|c|}
\hline Insulation & $\begin{array}{c}\text { Thickness } \\
(\mathbf{m})\end{array}$ & $\begin{array}{c}\lambda \text { value } \\
(\mathbf{W} / \mathbf{m} . \mathbf{K})\end{array}$ & $\begin{array}{c}\mathbf{R} \text { value } \\
\left(\mathbf{m}^{2} \mathbf{K} / \mathbf{W}\right)\end{array}$ \\
\hline Non-insulated & - & - & - \\
\hline EPS & 0.08 & 0.032 & 2.50 \\
\hline $\begin{array}{c}\text { MW+ SVR } \\
(\mu \mathrm{d}=0.3-20 \mathrm{~m})\end{array}$ & 0.05 & 0.032 & 1.56 \\
\hline $\begin{array}{c}\text { Calcium silicate } \\
\text { Perlite }\end{array}$ & 0.10 & 0.063 & 1.59 \\
\hline & 0.10 & 0.045 & 2.22 \\
\hline
\end{tabular}

\subsection{Joint around beam end}

Already in the 15th century, L.B. Alberti suggested an air space around beam ends to prevent wood decay (cited in [29]). Guizzardi et al [24] discovered indeed that even a small air space due to wood warping was enough to significantly lower the liquid moisture transport.

Previous research on beam ends often investigated the favourable situation of an air layer around the beam end [9-13, 18-19]. In Belgium however, we frequently encounter wooden beams where the joint between masonry and beam end is (partially or completely) filled with mortar. In this case, liquid water from wind-driven rain can more easily be transferred to the wooden beam.

In the test house, the joint between beam and masonry is executed in two ways: either completely filled with mortar or with a continuous air layer (except below and above the beam end) (Fig. 4). The hygrothermal influence of this joint is examined for an internally insulated wall with EPS, mineral wool and calcium silicate.
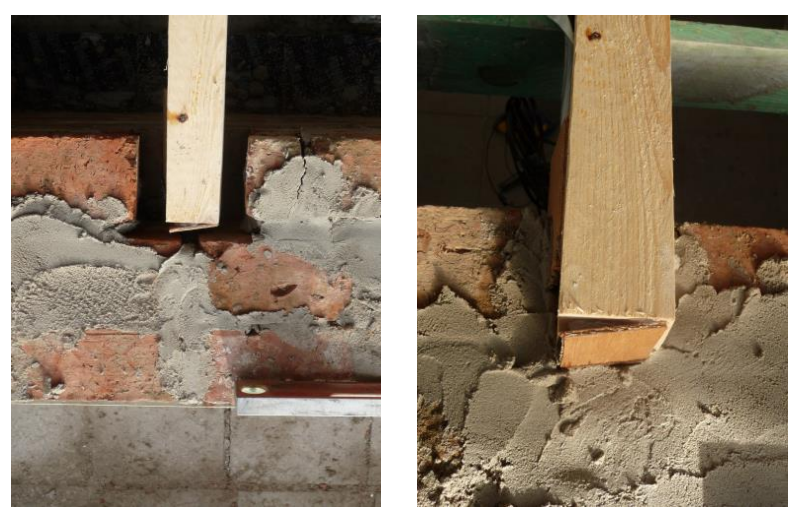

Fig. 4. Top view during construction of the beam with an air layer (left) and a joint filled with mortar (right).

\subsection{Thermal bridge at beam junction}

When interrupting the insulation layer between (and sometimes above and below) the beams, the local heat flux and consequently the drying potential increases. The positive impact has been demonstrated by numerical simulations [18-20]. Measurements on case studies showed acceptable moisture contents when the insulation was interrupted [12-13], however only a few measurements have been executed that allowed a direct comparison of the wall with and without insulation gap $[15,26]$. The thermal bridge increases the heat losses, making the renovation less energy-efficient.

The thermal insulation might also be interrupted for practical or conservatory reasons, not with the intention of promoting the drying rate, but to leave ceiling and flooring untouched.

To investigate the impact of the thermal bridge, the insulation of one of the test walls is interrupted next to the beam ends (Fig 5). No airtight sealing was provided, as if the wooden beam would have been inaccessible. However, as the beam is embedded in a completely filled mortar joint, no convective air flow is expected. In case of an air layer around the beam, the convective flow 
could strongly increase the risk of wood decay. Generally, it is thus advisable to provide an airtight sealing.

In real buildings, flooring and often ceiling are present above and below the beams. This has however not been installed in the test chamber. Therefore, the temperature at the beam junction and consequently the drying potential will be higher than if the floor structure would have been closed.

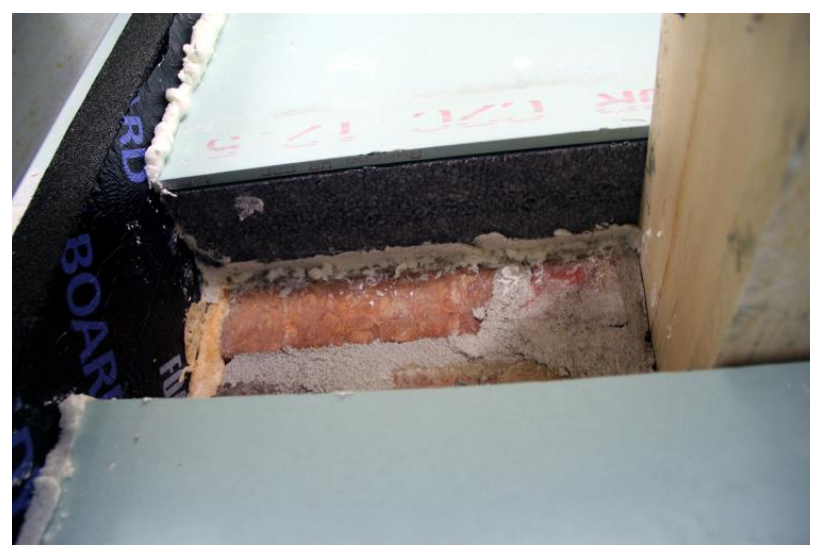

Fig. 5. Local interruption of the internal insulation, creating a thermal bridge which might promote the drying rate.

\subsection{Water repellent}

Wind-driven rain has often shown to have an important influence on the hygrothermal behaviour of internally insulated walls, and consequently, the moisture content of beam ends [2, 16-18]. Case studies and field tests with a low wind-driven rain load often lead to low moisture levels of the beam ends [9, 11-12, 14], high rain loads without sufficient protection can lead to unacceptable conditions $[2,17,26]$.

The application of a water repellent treatment is a possible solution to reduce the load of driving rain, while the external façade remains visually unaltered. However, water repellents should only be applied after a thorough review of the wall and the water repellent product. Some products have shown to be less effective [30]. The performance and durability of a water repellent agent depends on the product itself, but also on the type and characteristics of the treated material (e.g. porosity and pore size distribution: materials with very fine or very coarse pores are more difficult to treat durably), the condition of the material (a non-cohesive material is less likely to be treatable), the presence of cracks (treatment is generally not recommended if cracks are wider than $0.3 \mathrm{~mm}$, especially for frost-sensitive masonry) and the presence of salts (depending on type and concentration of salts, air humidity fluctuations and material sensitivity). Moreover, all water repellents reduce the drying speed of the wall, ranging from minor to very dramatic changes. The impact on the drying capacity strongly depends on the product, its penetration depth and the façade material itself [31]. Therefore, other moisture sources (e.g. rising damp) should first be eliminated. As the effectiveness of water repellents lowers in time, water repellents should be reapplied after some time. The frequency depends on the durability of each individual product.

To examine the impact of a water repellent, one of the test wall was treated 8 months after the construction of the walls. Then, 2.5 months after the treatment, the wall has been insulated from the inside using expanded polystyrene. This allows a direct comparison with the untreated test wall.

Laboratory measurements on the water repellent agent show that the product is very effective and has a small impact on the drying behaviour. Karsten tube measurements on the test wall show a reduction of the water absorption coefficient $\Delta_{15-5}$ of $97 \%$, confirming the effectiveness of the product.

\section{Results and discussion}

This section presents and discusses the results of the long-term field study, and essentially the measurements of wood moisture content at the beam end from September 2017 to January 2020. This paper aims for a comparative analysis between the different walls, as they all have the same exterior and interior boundary conditions. Even though both simplified and detailed wood decay models exist, this paper will not assess the risk of wood decay of the different beams, as this judgement is influenced by the specific boundary conditions valid for this specific field study (brick type and thickness, wind-driven rain load ...). However, by comparing the different walls, the impact of some parameters on the wood decay risk could be determined, which should be valid for other cases.

The subdivision of this chapter is the same as in section 2: first the different insulation materials, followed by the type of joint around the beam, the deliberate thermal bridge and finally the water repellent.

\subsection{Insulation materials}

All beam ends of the internally insulated walls show significantly higher moisture contents than the noninsulated wall. Moisture contents for all beams have a very similar course: the highest moisture content around March, the lowest around August (Fig. 6). From July 2017 to January 2018, a lot of rainfall has been measured, whereas the rest of 2018 was very dry with a high global solar radiation [32-33]. This could explain the difference in peak moisture contents between the beginning of 2018 and 2019. It also shows the impact of wind-driven rain and drying potential on the moisture content at the beam end.

The highest moisture content at the beam end are measured for the wall insulated with expanded polystyrene, having the highest vapour diffusion resistance. From the insulated walls, during the critical heating period, the lowest moisture content is measured at the beam end insulated with calcium silicate. The other capillary active system, perlite, leads to the lowest wood moisture content during the summer period, however more humid conditions were measured during the winter period. The measurements might also be 


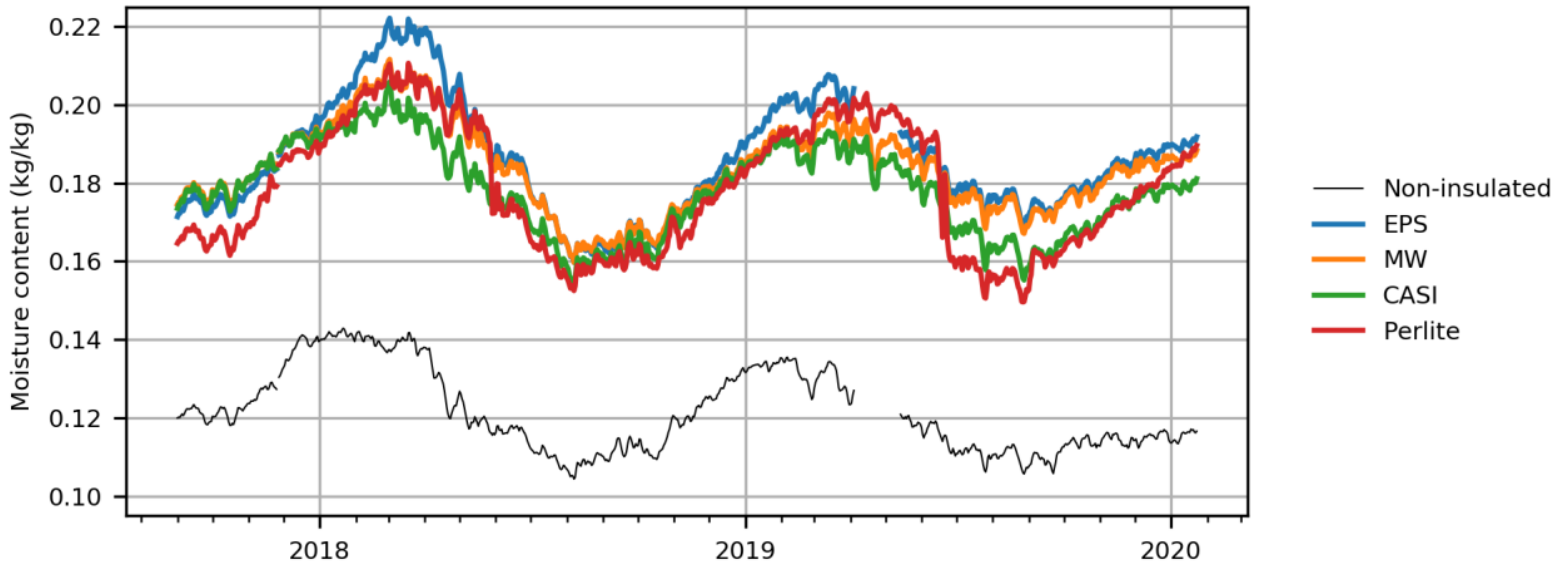

Fig. 6. Moisture content at the beam end for different insulation materials. Vapour tight systems are slightly more humid, however the differences between materials are small compared to the difference to the non-insulated wall.

influenced by a slight difference in thermal resistance between the insulation systems (Table 1).

These results are in line with earlier research, often concluding that capillary active systems lead to lower moisture conditions behind the insulation material and in the existing wall. Previous research generally found a clear contrast between materials. In this paper however, the difference in wood moisture content between the examined insulated walls (average wood moisture content between February and April 2018 equals 0.198 $\mathrm{kg} / \mathrm{kg}$ for calcium silicate and $0.216 \mathrm{~kg} / \mathrm{kg}$ for EPS) is small compared to the difference to the non-insulated wall $(0.139 \mathrm{~kg} / \mathrm{kg}$ during the same period).

The beam ends of the insulated walls are more humid because of the reduced drying potential, leading to much higher accumulated moisture from wind-driven rain in the existing wall, even when choosing a system that enhances inward drying. This is in line with earlier research [3], where it was concluded that the amount of wind-driven rain has a bigger influence on the hygrothermal behaviour of the wall than the choice of the insulation system.

\subsection{Joint around beam end}

For all the tested insulation materials, the beam ends with mortar joints are more humid than the ones with an air layer (Fig. 7). The course of all graphs is very similar. The difference between an air joint and mortar joint is $0.024 \mathrm{~kg} / \mathrm{kg}$ during the high moisture contents in February - April, and $0.037 \mathrm{~kg} / \mathrm{kg}$ during the lower moisture contents in August - October (average values over all materials and over both periods in 2018 and 2019).

The air layer serves as a hygric resistance, slowing down the moisture transport from the humid masonry to the beam end. When assessing the risk of wood decay, it is thus advisable to verify the layer between beam and masonry before assuming an air layer.

The moisture content sensor is positioned in the middle of the beam end. For the beam with an air joint, moisture contents could be higher at the top and bottom of the beam end where beam and masonry are in directly connected with a mortar layer.

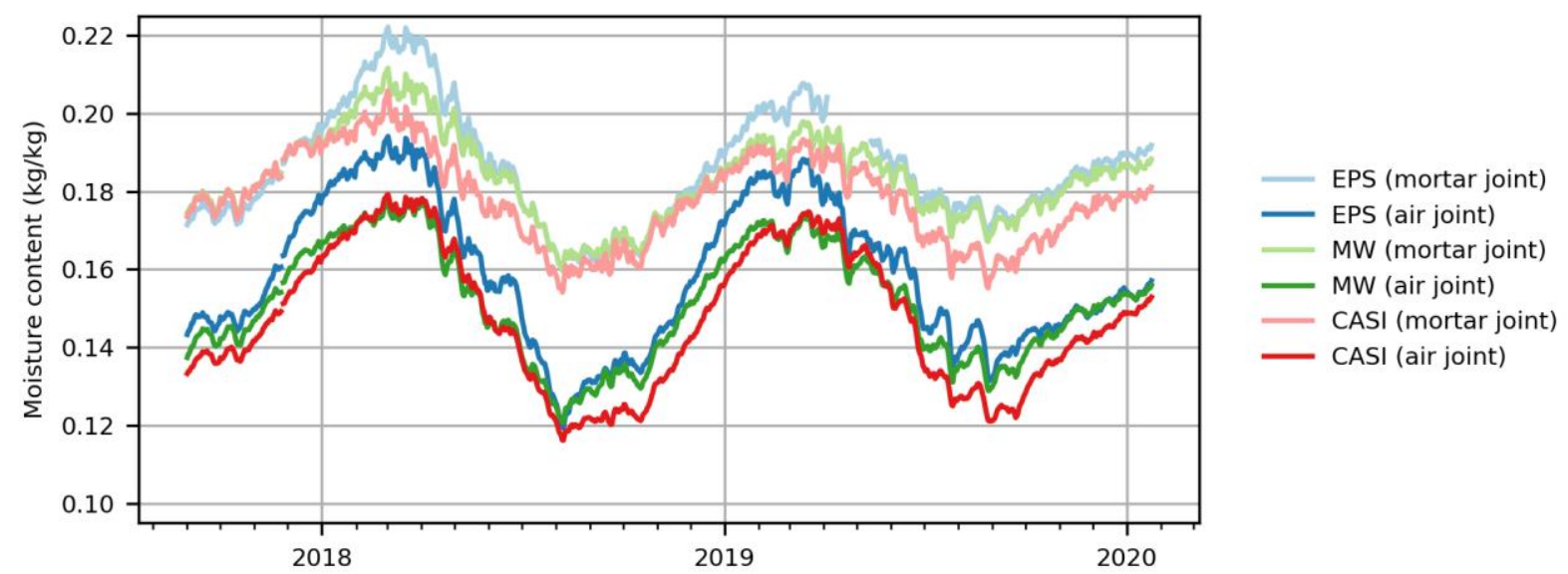

Fig. 7. Moisture content at the beam end for a mortar or an air connection around the beam end. In the case of an air joint, the moisture content is lower for all the insulation materials, indicating a higher hygric resistance compared to a mortar joint. 


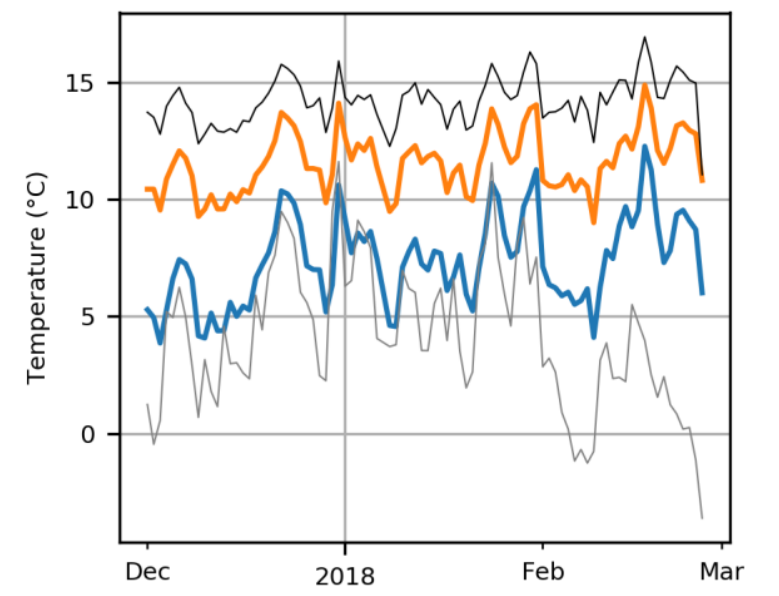

EPS - continuous (beam end)
EPS - non-insulated between beams

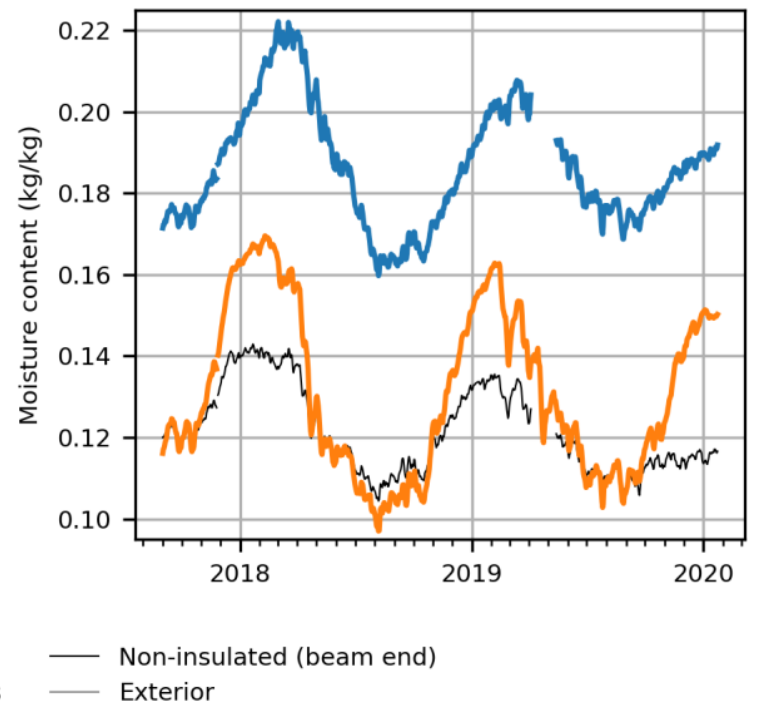

Fig. 8. Temperature (left) and moisture content (right) at the beam end for the test wall with a continuous and an interrupted insulation layer. The thermal bridge has a favourable impact on the moisture content of the wooden beam.

\subsection{Thermal bridge at beam junction}

When the area next to the beams is deliberately not insulated, the temperature at the beam end significantly increases. The average outdoor temperature during the plotted winter period (December 2018 to March 2019) equals $4.2^{\circ} \mathrm{C}$. During the same period, the average temperature at the beam end equals $7.4^{\circ} \mathrm{C}$ for the continuously insulated test wall, $11.6^{\circ} \mathrm{C}$ for the test wall with thermal bridge and $14.2^{\circ} \mathrm{C}$ for the non-insulated wall. The temperature at the beam end with thermal bridge is closer to the non-insulated situation than to the continuous insulated one (Fig. 8, left).

The moisture content measured at the beam end is significantly lower in case of a thermal bridge. During summer, moisture contents are as low as the noninsulated case (Fig. 8, right). Compared to the wall without thermal bridge, the wood moisture content for the wall with interrupted insulation is $0.052 \mathrm{~kg} / \mathrm{kg}$ lower from February to April and $0.062 \mathrm{~kg} / \mathrm{kg}$ lower from August to October (values averaged over these periods, both in 2018 and 2019).

The thermal bridge thus locally increases temperatures and drying potential, leading to more favourable hygrothermal conditions. During the heating season, the surrounding part of the wall gets more humid. This moisture is eventually redistributed to the beam, but the beam end is still significantly drier than the situation with continuously placed insulation.

As no flooring or ceiling was placed, the indoor air could easily heat up the beam end. If the flooring would have been closed, it is very likely that temperature between flooring and ceiling is lower than the room temperature, which would lower the favourable impact of the thermal bridging on the moisture content.

\subsection{Water repellent}

At the start of measurements in January 2017, the wood moisture content of the hydrophobized wall is higher than the untreated wall (Fig. 9). Starting from mid-2017, the two lines cross and with time going, the difference between treated and untreated wall increases. After treatment, the moisture (most probably built-in moisture from the wall construction) took thus longer to dry out, confirming the reduced drying speed after applying water repellents.

When the built-in moisture is evaporated, the wooden beam end of the hydrophobized wall is significantly drier than the untreated wall. The strong reduction of the wind-driven rain absorption has a favourable impact on the hygrothermal conditions at the beam end.

A field study in Denmark showed that the wooden beams of internal insulated hydrophobized walls were more humid during winter time than the walls without treatment [26]. This is not in line with the measurements in this paper. This might be explained by a less efficient water repellent agent, or by the presence of built-in moisture which takes longer to dry out for a treated wall.

As the presented measurements show the impact of the reduced drying speed of treated walls, it seems advisable to apply water repellents when the wall is expected to be rather dry. The walls examined in this paper all show the driest period at the end of the summer (due to higher temperatures and solar radiation), indicating that it might be a good period to apply a water repellent. Similarly, after removal of a moisture source (e.g. rising damp or a leaking gutter), the wall should be allowed to dry out before treating with a water repellent. For walls with a thickness of $30 \mathrm{~cm}$, one should consider a drying period of several months to a year, depending on the façade materials and the drying conditions (temperature, ventilation, relative humidity of the air and presence of layers such as paintings). 


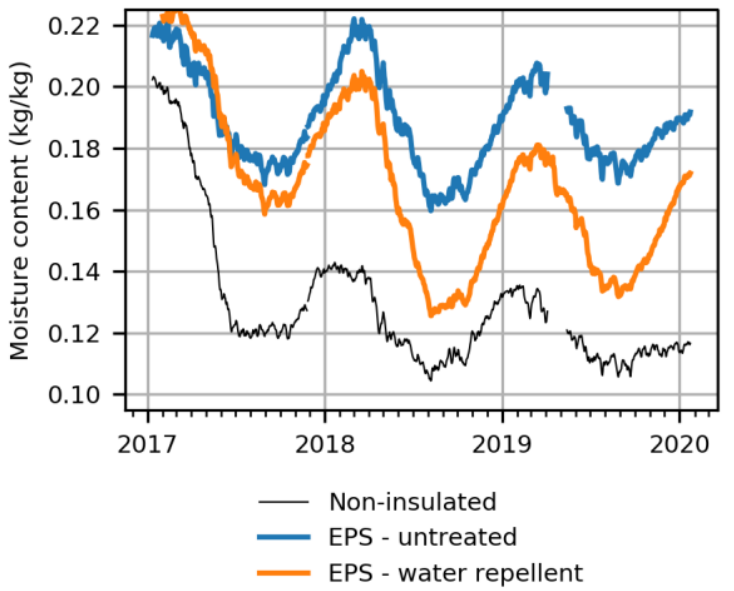

Fig. 9. Moisture content at the beam ends of the walls with and without a water repellent treatment. The water repellent has a favourable impact on the moisture content, but reduces the drying rate.

\section{Conclusion}

Old buildings often have wooden beams as a floor structure, embedded in a single-leaf masonry wall. Due to the reduced drying potential of internally insulated walls, the decay risk of these wooden beams might increase. This paper discussed the measurements of a long-term field study on different internally insulated test walls with embedded wooden beams.

The moisture content of the wall, especially determined by the amount of rain water absorbed by the wall, plays a crucial role in the moisture safety of wooden beams. Indeed, as the wind-driven rain load on the test walls is rather high and the drying potential is reduced by applying internal insulation, a strong increase of the wood moisture content between insulated and noninsulated wall is noticed. When the liquid transport of the absorbed rain water to the beam is lower, for instance in the case of an air layer around the beam instead of mortar, lower moisture contents are measured.

All measures to lower the moisture content of the wall has shown a favourable effect on the conditions of the wooden beam. In the presented paper, this is shown by the positive impact of a water repellent treatment (this treatment is only applicable after a thorough review of the wall and the water repellent product, and thus certainly not in all situations) and an interruption of the insulation layer at the beam junction.

Other situations leading to low rain loads are thus expected to have a similar positive effect, for instance a favourable orientation with respect to wind-driven rain, an adequate roof overhang and low-absorbing renders.

The measurements show only a small positive impact of the use of vapour open capillary active insulation materials. The choice of insulation material could thus not be seen as a sufficient solution towards moisture-safe application of internal insulation in combination with wooden beam ends.
The results in this paper have been obtained within the CORNET project IN2EuroBuild, funded by BMWi / AiF (Germany) and DGO6 (Belgium - Wallonia). The financial support is gratefully acknowledged.

\section{References}

1. European Comission, Building and renovating. The European Green Deal (2019)

2. P. Johansson, S. Geving, C.-E. Hagentoft, B.P. Jelle, E. Rognvik, A.S. Kalagasidis, B. Time, Interior insulation retrofit of a historical brick wall using vacuum insulation panels: Hygrothermal numerical simulations and laboratory investigations, Building and Environment, 79, 31-45 (2014)

3. T. De Mets, A. Tilmans, X. Loncour, Hygrothermal assessment of internal insulation systems of brick walls through numerical simulation and full-scale laboratory testing, Energy Procedia, 132, 753-758 (2017)

4. E. Vereecken, L. Van Gelder, H. Janssen, S. Roels, Interior insulation for wall retrofitting - A probabilistic analysis of energy savings and hygrothermal risks, Energy and Buildings, 89, 231244 (2015)

5. T. De Mets, A. Tilmans, E. Vereecken, S. Roels, Capillair actieve isolatiesystemen: een innovatieve oplossing voor binnenisolatie?, WTCB-Contact, 2019/5, 10-13 (2019)

6. E. Vereecken, S. Roels, Capillary active interior insulation: do the advantages really offset potential disadvantages?, Materials and Structures, 48, 30093021 (2015)

7. J. Grunewald, U. Ruisinger, P. Haupl, The Rijksmuseum Amsterdam - hygrothermal analysis and dimensioning of thermal insulation, $3 r d$ International Building Physics, Canada, 345-352 (2006)

8. J. Zhao, J. Grunewald, U. Ruisinger, S. Feng, Evaluation of capillary-active mineral insulation systems for interior retrofit solution, Building and Environment, 115, 215-227 (2017)

9. P. Kopecký, K. Staněk, M. Bureš, J. Richter, J. Tywoniak, Experimental investigations of wooden beam ends in masonry with internal insulation, Energy Procedia, 132, 682-687 (2017)

10. E. Vereecken, S. Roels, Wooden beam ends in combination with interior insulation: An experimental study on the impact of convective moisture transport, Building and Environment, 148, 524-534 (2019)

11. U. Ruisinger, Long-term measurements and simulations of five internal insulation systems and their impact on wooden beam heads, 2nd Central European symposium on building physics, Vienna, 313-319 (2013)

12. T.K. Hansen, S.P. Bjarløv, R.H. Peuhkuri, M. Harrestrup, Long term in situ measurements of hygrothermal conditions at critical points in four 
cases of internally insulated historic solid masonry walls, Energy and Buildings, 172, 235-248 (2018)

13. M. Harrestrup, S. Svendsen, Full-scale test of an old heritage multi-storey building undergoing energy retrofitting with focus on internal insulation and moisture, Building and Environment, 85, 123-133 (2015)

14. M. Morelli, L. Rønby, S.E. Mikkelsen, M.G. Minzari, T. Kildemoes, H.M. Tommerup, Energy retrofitting of a typical old Danish multi-family building to a "nearly-zero" energy building based on experiences from a test apartment, Energy and Buildings, 54, 395-406 (2012)

15. T. Loga, Erfahrungen mit der energetischen Modernisierung eines Gründerzeitgebäudes, Beitrag zur Baufachtagung (2004)

16. H. Stopp, P. Strangfeld, T. Toepel, E. Anlauft, Messergebnisse und bauphysikalische Lösungsansätze zur Problematik der Holzbalkenköpfe in Außenwänden mit Innendämmung, Bauphysik, 32, 61-72, (2010)

17. M. Guizzardi, J. Carmeliet, D. Derome, Risk analysis of biodeterioration of wooden beams embedded in internally insulated masonry walls, Construction and Building Materials, 99, 159-168 (2015)

18. M. Morelli, T.R. Nielsen, G.A. Scheffler, S. Svendsen, Internal Insulation of Masonry Walls with Wooden Floor Beams in Northern Humid Climate, Thermal Performance of the Exterior Envelopes of Whole Buildings XI, US (2010)

19. M. Morelli, S. Svendsen, Investigation of interior post-insulated masonry walls with wooden beam ends, Journal of Building Physics, 36, 265-293 (2013)

20. M. Harrestrup, S. Svendsen, Internal insulation applied in heritage multi-storey buildings with wooden beams embedded in solid masonry brick façades, Building and Environment, 99, 59-72 (2016)

21. H.J.P. Brocken, O.C.G. Adan, L. Pel, Moisture transport properties of mortar and mortar joint: a NMR study, Heron, 42, 55-69 (1997)
22. H. Derluyn, H. Janssen, P. Moonen, J. Carmeliet, Moisture transfer across the interface between brick and mortar joint, 8th Symposium on Building Physics in Nordic Countries, Denmark (2008)

23. H. Derluyn, H. Janssen, J. Carmeliet, Influence of the nature of interfaces on the capillary transport in layered materials, Construction and Building Materials, 25, 3685-3693 (2011)

24. M. Guizzardi, D. Derome, R. Vonbank, J. Carmeliet, Hygrothermal behavior of a massive wall with interior insulation during wetting, Building and Environment, 89, 59-71 (2015)

25. K. Calle, N. Van Den Bossche, Towards understanding rain infiltration in historic brickwork, Energy Procedia, 132, 676-681 (2017)

26. T. Odgaard, S.P. Bjarløv, C. Rode, Influence of hydrophobation and deliberate thermal bridge on hygrothermal conditions of internally insulated historic solid masonry walls with built-in wood, Energy and Buildings, 173, 530-546 (2018)

27. T.K. Hansen, S.P. Bjarløv, R. Peuhkuri, The effects of wind-driven rain on the hygrothermal conditions behind wooden beam ends and at the interfaces between internal insulation and existing solid masonry, Energy and Buildings, 196, 255-268 (2019)

28. K. Ueno, J.W. Lstiburek, Field Monitoring of Embedded Wood Members in Insulated Masonry Walls in a Cold Climate, BEST4 Conference (2015)

29. C. B. Cestari, A. Lucchio, Interventions on historical building timber floors: Retractable visible? invasive - not visible? A case study, Historical Constructions, 837-846 (2001)

30. S. Couto, T.D. Gonçalves, J.M.G. Lopes, Drying of Red Ceramic Brick. Effect of five Siliconebased Water-Repellent Treatments, Hydrophobe VI, 81-92 (2011)

31. Belgian Building Research Institute (BBRI), Waterwerende oppervlaktebehandeling, Technische Voorlichting, 224 (2002)

32. Koninklijk Meteorologisch Instituut, Klimatologisch jaaroverzicht 2017 (2018).

33. Koninklijk Meteorologisch Instituut, Klimatologisch jaaroverzicht 2018 (2019). 